\title{
Movilidad ascendente de la inmigración en España: ¿asimilación o segmentación ocupacional? ${ }^{1}$
}

\author{
Antonio Martín Artiles \\ Pedro López-Roldán \\ Óscar Molina \\ Universitat Autònoma de Barcelona. Departament de Sociologia \\ antonio.martin@uab.es; pedro.lopez.roldan@uab.es; oscar.molina@uab.es
}

\section{Resumen}

La posibilidad de movilidad ascendente de la población inmigrante es un factor importante a la hora de explicar su integración social. Asimismo, a nivel individual, la expectativa de movilidad puede contribuir a aumentar o disminuir la incertidumbre socioeconómica. El objetivo de este artículo es analizar la movilidad ocupacional vertical de la inmigración. Tratamos de explicar cuales son las variables clave en el acceso de los inmigrantes a los salarios altos. Una regresión logística nos permite ver como interactúan las variables individuales, como la antigüedad y el nivel de estudios, con las variables estructurales, como el tamaño de la empresa y el sector de actividad. Además, un análisis factorial de correspondencias múltiples nos permite agrupar todas las variables y ofrecer una tipología que clasifica las trayectorias laborales con arreglo a la segmentación del mercado de trabajo.

Palabras clave: inmigración; movilidad ocupacional; trayectorias; capital humano; segmentación; salarios; antigüedad; contrato de trabajo; empresa; sector de actividad; asimilación ocupacional.

Abstract. Upward Occupational Mobility of Immigrant Workers in Spain: Assimilation or Occupational Segmentation?

Possibilities for occupational mobility are an important factor in the explanation of the integration of immigrant workers into receiving societies. Moreover, at the individual level, the prospects for upward occupational mobility determine the uncertainty facing immi-

1. Esta investigación forma parte del Proyecto Gusto (SHH-CT, 2009-225301) del VII Programa Marco de la Comisión Europea. La fuente de información de la MCVL ha sido explotada para el proyecto "Emigració, ocupació i cohesió social”, financiado por la Fundació La Caixa, convenio 10984. Expresamos nuestro agradecimiento a los comentarios de Guglielmo Meardi (Universidad Warwick), Axel van der Berg (McGill University), Faustino Miguélez, Ramón Alós, Fernando Esteban y Sara Moreno (Universitat Autònoma de Barcelona). 
grant workers. In this paper, we examine the upward occupational mobility of immigrant workers in Spain. We attempt to explain the key variables determining immigrants' access to high wages. A multinomial logistic regression examines the interaction between individual variables such as age and education level, and structural variables such as company size and sector. In addition, a factor analysis allows us to group these variables into a typology that classifies career paths according to labour market segmentation.

Key words: immigration; occupational mobility; trajectories; human capital; segmentation; earnings; tenure; establishment size; sector; assimilation.

\begin{aligned} & \multicolumn{2}{c}{ Sumario } \\ & Introducción $\begin{array}{l}\text { Seccion II. Análisis de la asimilación } \\ \text { ocupacional y salarial }\end{array} \\ &$ Sección I: aproximación teórica y metodológica a la movilidad \\ & ocupacional de la población inmigrante Sección III. Análisis de la segmentación \\ & Algunas conclusiones \\ & Referencias bibliográficas \end{aligned}

\section{Introducción}

El objetivo de este artículo es analizar la movilidad ocupacional ascendente o vertical de los trabajadores inmigrantes en España, esto es, el cambio y la promoción de categorías profesionales. Hay muy pocos estudios sobre la movilidad ocupacional ascendente de los inmigrantes, y la mayor parte de ellos han sido hechos a partir de aproximaciones cuantitativas indirectas, como es, por ejemplo, a través de los cambios en los regímenes de la Seguridad Social, aunque también se han realizado algunos estudios cualitativos referidos a determinados orígenes de los inmigrantes. Una de las razones de este vacío en la literatura es que el fenómeno inmigratorio es todavía reciente en este país y la disponibilidad de datos es escasa (véase Escrivá, 2000; Pumares et al., 2007; Reher et al., 2007; Sanabria, 2008; Pajares, 2008; Izquierdo et al., 2009).

Nuestra investigación se basa en un estudio de los cambios de posiciones de categorías profesionales de la Seguridad Social, así como en las variaciones de las cotizaciones a la misma. En este último caso, como variable proxy que nos informa indirectamente sobre los salarios. En este sentido, hablaremos también de trayectoria laboral. Por consiguiente, tanto la temática elegida como el enfoque y la metodología elegida son novedosos y el tipo de fuente justifica las razones de oportunidad de este artículo. La fuente es la Muestra Continua de Vidas Laborales (MCVL), que constituye un recurso de información inestimable. Otro argumento para esgrimir la razón de oportunidad del mismo es que el estudio de la asimilación ocupacional y la movilidad ascendente son hoy de interés, porque nos ofrece información acerca de los riesgos y la incertidumbre a los que están expuestos los diferentes grupos de trabajadores, a la vez que constituye un indicador de integración social (Crouch, 2008, 2009). El interés y la motivación que hoy tiene la movilidad laboral estriban en formar 
parte de la Estrategia Europea de Empleo. De hecho, el año 2006 fue declarado por la Comisión como Año Europeo de la Movilidad de los Trabajadores. La Comisión Europea (European Commission, 2006 y 2008) sostiene que la movilidad laboral aporta flexibilidad a los mercados de trabajo, permite reducir el desempleo, bajar los niveles de pobreza, y facilita el ajuste entre la oferta y la demanda de trabajo en los mercados locales. Además, la movilidad ocupacional ascendente de los trabajadores contribuye a mejorar su posición socioeconómica, su categoría profesional y su estatus social, y, por consiguiente, reduce el riesgo de desempleo y de pobreza. Así pues, la movilidad laboral ascendente tiende a proporcionar seguridad laboral y reduce el riesgo y la incertidumbre de los trabajadores (Zimmerman, 2009; Brücker, 2009).

El modelo analítico que hemos construido se ha basado en el análisis de variables relacionadas con las características de los individuos, desde el lado de la oferta, y variables estructurales que informan de las características de la demanda. En particular, nos interesa analizar cuáles son los factores principales que explican la movilidad ocupacional vertical o la promoción de categoría profesional de los inmigrantes. La finalidad es analizar el peso que tienen las características de los individuos y el que tiene la estructura económica, donde se insertan los inmigrantes, como variables explicativas de la movilidad. Dicho de otra manera: ¿Qué variables explican que los inmigrantes alcancen salarios más elevados?

El artículo se estructura en tres secciones. En la primera sección, se describe la aproximación teórica y metodológica al estudio de los patrones de movilidad ocupacional y salarial. A continuación, la segunda sección analiza la asimilación ocupacional tomando como referencia a los salarios. Finalmente, la tercera sección aborda la segmentación del mercado de trabajo tomando como referencia las categorías profesionales.

\section{Sección I: aproximación teórica y metodológica a la movilidad ocupacional de la población inmigrante}

\section{El concepto de movilidad ocupacional ascendente}

En la literatura sociológica, el término movilidad ocupacional hace referencia a los movimientos de los individuos y de los grupos entre las distintas posiciones socioeconómicas (Giddens, 1991: 260) y se relaciona con la estratificación social. La movilidad ocupacional vertical es el término utilizado para explicar los movimientos ascendentes o descendentes en la escala de categoría socioeconómica (véanse Horan, 1974; Giddens, 1991; Gagnon, 2009, entre otros). Por tanto, el hecho de ascender o descender alude a movimientos en relación con la renta, con los salarios, con el prestigio social y con el estatus social y profesional de los individuos. La movilidad horizontal se refiere a cambios de lugar de residencia o bien a cambios entre sectores de actividad económica, con posibles repercusiones sobre las posiciones de categoría socioeconómica de los individuos. Por razones de espacio, en éste artículo sólo atenderemos a la movilidad vertical. 
Asimismo, utilizamos también el concepto más genérico de trayectoria. La función del concepto de trayectoria laboral es ofrecer una perspectiva temporal sobre la sucesión de cambios de posiciones en las categorías profesionales y, por tanto, nos será útil para observar el proceso de inserción laboral y de movilidad de los inmigrantes (entre el primer y el último contrato de trabajo). Los estudios sobre trayectorias laborales a menudo han formado parte de los estudios de juventud, de movilidad laboral, de transición entre escuela y mercado de trabajo y los referidos a la estratificación social, de ahí su carácter polisémico (véanse, entre otros, Spillerman, 1977; Casal, 1997; Henríquez; Uribe-Echevarria, 2002; Dávila y Ghiardo, 2005).

La movilidad se ha estudiado desde otras dos grandes perspectivas. La primera, examinando las propias carreras de los individuos a través de los ascensos y los descensos de categorías profesionales, lo que se conoce como movilidad intrageneracional, que es la que nosotros adoptamos en este estudio sobre la inmigración. En los estudios de inmigración, la movilidad intrageneracional ha tomado habitualmente como referencia el último trabajo de los inmigrantes en su país de origen y después el primer trabajo en el país de acogida y los sucesivos cambios de posiciones (véase Chiswick, 2005; Green, 1999, entre otros). Nosotros sólo consideraremos en las páginas siguientes la movilidad intrageneracional en el país de acogida ${ }^{2}$.

La movilidad ascendente ha sido habitualmente tomada en los estudios como un indicador de "sociedad abierta", de mercado laboral abierto, que ofrece igualdad de oportunidades, que permite la promoción y el desarrollo de las carreras profesionales de los individuos (Horan, 1974; Giddens, 1991, entre otros). Ello vale también para la inmigración. En este sentido, las recomendaciones de la OCDE y de la Unión Europea enfatizan la idea de flexibilizar el mercado de trabajo mediante una mayor movilidad laboral para luchar contra el desempleo y la pobreza (Gagnon, 2009). La movilidad descendente es menos frecuente que la anterior $\mathrm{y}$, además, ha sido menos estudiada. Algunos estudios han hallado que las mujeres tienen mayores riesgos de movilidad descendente a tenor de las desigualdades de género, lo que se refleja en el tipo de contrato laboral, como el empleo temporal, el trabajo a tiempo parcial, menores salarios, mayor desempleo, salidas y reincorporaciones posteriores en el mercado laboral en peores condiciones.

Un problema en discusión son los indicadores de la movilidad. Tradicionalmente, se ha considerado el cambio de una profesión de cuello azul a otra de cuello blanco como un indicador de movilidad laboral ascendente. Sin embargo, esto hoy no es suficiente, ya que muchos puestos de trabajo de cuello azul tienen mejores retribuciones salariales que los de cuello blanco y, además, muchos trabajos de cuello blanco se han descualificado a través de la automatización y la taylorización del proceso productivo en las tareas admi-

2. La segunda perspectiva es la movilidad intergeneracional. Ésta se refiere a la segunda generación de los inmigrantes. Esta segunda perspectiva, subrayamos, no la hemos estudiado en la presente investigación. 
nistrativas. El problema de los indicadores de la movilidad ha sido abordado por Horan, quien ha enfatizado la necesidad de adoptar un enfoque muldimensional: no basta con analizar las variables relacionadas con los atributos de los individuos en los términos del capital humano, es necesario complementar el análisis incluyendo otras variables estructurales e institucionales para explicar la movilidad ocupacional.

El tamaño de la empresa y el sector de actividad tienen una notable influencia en la movilidad ocupacional vertical. Como ha puesto de relieve Osterman (1985), las grandes empresas tienen organigramas que hacen posible el desarrollo de carreras profesionales a través de una escala de jerarquías, de organigramas amplios que no poseen las pequeñas empresas. Lo mismo ocurre con el sector de actividad: las características tecnológicas y organizativas del sector condicionan también el desarrollo de carreras profesionales. En pocas palabras, el estudio de la movilidad ocupacional ascendente es también un análisis de la diferenciación social, de estudio de las jerarquías y de las carreras profesionales en una escala de estatus y prestigio. Por consiguiente, la movilidad ocupacional se ha venido estudiando preferentemente desde la dimensión vertical, porque está más estrechamente relacionada con la estratificación y la desigualdad social.

\section{Enfoques teóricos}

En la literatura especializada, encontramos que los factores explicativos de la movilidad ocupacional ascendente han sido analizados fundamentalmente a partir de las teorías del capital humano, que ha prestado atención a las variables individuales que informan sobre el nivel de educación, los años de escolarización, la edad de abandono de la escuela y el aprendizaje en el puesto de trabajo, entre otras variables (Becker, 1983). Desde este enfoque, se han tomado los salarios como un importante indicador del proceso de asimilación ocupacional.

Otro enfoque de la movilidad ocupacional ha buscado en las teorías de la segmentación del mercado de trabajo otras variables explicativas de la desigualdad y de la estratificación social, como son el género, la etnia, la categoría profesional y la clase (Piore, 1983). Por consiguiente, a continuación, dedicamos atención a estos dos enfoques.

1. Por un lado, desde la perspectiva de nivel micro, la teoría del capital humano ha venido sosteniendo el peso explicativo que tienen las características de los individuos en la movilidad ocupacional ascendente, como el nivel de estudios, el conocimiento, el aprendizaje formal e informal en el puesto de trabajo y la experiencia profesional, entre otras (Becker, 1983). Un ejemplo de este tipo de análisis lo encontramos en la investigación de Coughlan (1998: 190-191) sobre la movilidad ascendente de los vietnamitas en Australia, que analiza variables tales como el nivel de estudios primarios y secundarios, la posesión de un titulo universitario, los años de antigüedad en el mercado de trabajo, el cono- 
cimiento de la lengua y el número de años en situación de desempleo. Otros ejemplos parecidos los encontramos en los estudios de Toussaint-Comeau (2006) y Redstone (2006) sobre los inmigrantes latinos en Estados Unidos: para éstos investigadores, la educación formal, el aprendizaje en la empresa y la experiencia en el mercado tiene efectos positivos en la adquisición de un mayor estatus profesional y en la convergencia salarial. Desde esta perspectiva, se suele concluir en la defensa de la tesis de la convergencia o asimilación ocupacional ${ }^{3}$ de la inmigración, con lo cual se da a entender que, a la larga, la inmigración alcanza las posiciones de empleo y de retorno económico parecido al que tiene la población autóctona cuando la primera reúne los requisitos de cualificación profesional (Tubergen, 2008).

Una línea sólida de investigación fundamentada en este enfoque, y tomada como referencia en el debate sobre las políticas de inmigración, la encontramos en el caso de Canadá. Algunos investigadores, como Green (1999), han examinado la distribución ocupacional de la inmigración y su movilidad a lo largo de los años a partir del censo de población en dicho país. Este autor toma como indicador de movilidad laboral ascendente las ganancias salariales según cohortes de entrada de la inmigración. Green demuestra que la movilidad laboral ascendente es más rápida para los inmigrantes que para los nativos, porque Canadá tiene un sistema de reclutamiento selectivo (por puntos) de inmigración cualificada ${ }^{4}$ (véase también Bloom et al., 1995; Schaafsma y Sweetman, 2001; Ferrer et al., 2006, entre otros).

Otro estudio que confirma unas conclusiones parecidas sobre la asimilación ocupacional es el de Goldmann et al. (2009: 16). Estos investigadores exploran también la distribución ocupacional de los inmigrantes y encuentran que éstos ascienden más rápidamente que los propios trabajadores autóctonos. Los indicadores utilizados en el estudio de la movilidad ocupacional ascendente fueron el cambio de posición en una escala de diez categorías ocupacionales establecidas en

3. La «asimilación» de los inmigrantes es un concepto más amplio que el habitualmente utilizado desde la teoría del capital humano. La asimilación hace también referencia a la adopción de valores, de la cultura y de las tradiciones de la sociedad de acogida, lo que está relacionado con la idea de mantener a la sociedad cohesionada. Sin embargo, resulta mucho más fácil mesurar la asimilación con el indicador de los salarios, como hace la teoría del capital humano (Sjaastad, 1962).

4. Las bases de la actual política de inmigración en Canadá fueron establecidas en 1967. Sus características principales son:

a) Énfasis en el reclutamiento de inmigrantes con cualificaciones altas y de forma selectiva.

b) Énfasis en sincronizar el flujo de entrada de la inmigración con las necesidades de la demanda del mercado de trabajo.

c) La introducción de un sistema de puntos, orientado hacia las altas cualificaciones, pero también hacia la reunificación familiar.

d) A partir de 1970, reforzamiento de la dimensión de los derechos humanos para admitir a los refugiados políticos.

La apertura hacia la reunificación familiar y hacia los refugiados políticos comportó un decrecimiento de la "asimilación ocupacional», por ello, a partir de 1978, se volvió a enfatizar el criterio selectivo orientado a captar inmigrantes con cualificaciones altas procedentes de otros países no europeos (Bloom et al., 1995: 989-990). 
el SOC (Standard Occupational Classification), que se subdividen en cuatro grupos. A y $\mathrm{B}$ recogen a las cualificaciones más altas y $\mathrm{C}$ y $\mathrm{D}$, las menos cualificadas. La particularidad de su hallazgo es que, en los grupos A y B, se produce una rápida promoción para los inmigrantes cualificados, de modo que, apenas a los cuatro años de su llegada al país, el 60\% de los hombres y el $64 \%$ de las mujeres están en este grupo. Pero ya desde los primeros seis meses de llegada al país, el $40 \%$ de los hombres y el $28 \%$ de las mujeres forman parte de los grupos A y B del SOC. Esta temprana inserción en ocupaciones altas y con salarios elevados difiere mucho de lo encontrado en otras investigaciones realizadas en Europa. En el caso canadiense, ello se debe a una restrictiva y selectiva política de reclutamiento de la inmigración en origen, de modo que muchos de los inmigrantes ya poseen una titulación universitaria. La proporción de inmigrantes con estudios universitarios es en dicho país superior a la de otros países como Estados Unidos o Australia (véase McAllister, 1995; Chiswick, 2005).

2. Por otro lado, desde la perspectiva macrosocial, las teorías de la segmentación sostienen la tesis de la estratificación y ponen el énfasis en las variables que marcan diferencias sociales, como el género, la etnia y la clase (Parella, 2003), además de otras variables estructurales, como el sector de actividad, el tamaño de la empresa y los segmentos del mercado de trabajo donde se insertan los inmigrantes.

Uno de los hallazgos del enfoque de la segmentación es la estratificación del mercado laboral por grupos étnicos. La etnoestratificación es el término acuñado para explicar las diferencias sociales y étnicas. Pero también con este concepto se trata de dar cuenta de la inserción de los inmigrantes en nichos específicos del mercado laboral, lo que dificulta su movilidad entre segmentos y limita la movilidad ascendente (véase Piore, 1983; Sabel, 1986; Piore y Sabel, 1990; Villa, 1990; Reyneri, 2006; Miguélez y Recio, 2008; Cachón, 2009, entre otros) $)^{5}$.

Por consiguiente, un aspecto distintivo de este enfoque es que la movilidad ascendente de los inmigrantes no se produce fácilmente o bien no es tan rápida como en el caso canadiense. Por el contrario es lenta o «retardada», como pone de relieve Kogan (2003) para el caso de Alemania y, además, genera una estratificación de posiciones laborales. En el caso del Reino Unido, Gordon (1995) ha explicado la influencia que tiene la dimensión estructural en la movilidad ocupacional, como son las propias características cualitativas del mercado laboral local, el sector de ocupación, la estructura de categorías profesionales, las organizaciones, las empresas, los sindicatos, las normas y la estabilidad de empleo. La consideración de estas variables contrasta con la visión ortodoxa de la teoría del capital humano que presta más atención a las características de los individuos. Otro estudio de Dickens y McKnight (2008) concluye que la asimilación salarial es tardía por razones étnicas relacionadas con el origen

5. Para una clasificación ordenada y actualizada de las teorías de la segmentación, véase Polavieja (2003). Para una visión crítica sobre los factores estructurales de la segmentación, véase Polavieja (2006). 
de los inmigrantes, o bien relacionadas con el desconocimiento de la lengua, pero también porque el mercado de trabajo está fuertemente segmentado, estratificado, y los inmigrantes están ocupados en empleos precarios y de bajos salarios.

En suma, nuestra hipótesis es que la movilidad ascendente no se puede explicar sólo en términos de asimilación y convergencia salarial. El proceso de asimilación y convergencia dependen de diversas variables que interactúan. En la asimilación ocupacional, intervienen tanto las características y los atributos de los individuos, como las características estructurales del puesto de trabajo, de la empresa y del sector de actividad. En los últimos años, se han venido realizando estudios que explican de manera más compleja el problema de la movilidad ocupacional, a tenor de la interacción entre distintas variables. Algunos autores, entre otros, Bloom et al. (1995), Coughlan (1998) y Piché et al. (2002), sugieren la existencia de varios factores explicativos que interactúan en la movilidad ocupacional. Son los siguientes:

1. El capital humano, el nivel de estudios y la cualificación profesional, formal e informal, adquirida en el puesto de trabajo.

2. El conocimiento de la lengua y el fondo cultural.

3. La antigüedad en el mercado laboral, porque indica el conocimiento de las características y las oportunidades que se pueden encontrar en el mercado laboral local.

4. La existencia, en la sociedad de acogida, de segregación laboral por género y etnia.

5. La existencia de una política de acogida y de provisión de programas públicos y servicios de formación para los inmigrantes.

6. El grado de segmentación del mercado de trabajo.

7. La existencia de una política basada en el recurso a la inmigración como «ejército industrial de reserva» en periodos de expansión económica (McAllister, 1995) y el nivel de desempleo y desigualdad en la sociedad de acogida (Tubergen, 2008).

\section{Movilidad ocupacional de la inmigración en España}

En el caso español, el modelo económico intensivo en mano de obra (y salarios bajos) ha atraído fundamentalmente inmigrantes de baja cualificación profesional, con "perfil obrero" (Reher y Requena, 2009). El reclutamiento de mano de obra inmigrante ha comportado un flujo de inmigración destinado a insertarse en ciertos segmentos de empleo intensivos en mano de obra: agricultura, construcción, hostelería y servicio doméstico. Estos segmentos de empleo sólo proporcionan una limitada movilidad ocupacional ascendente. Por consiguiente, resultan menores las promociones de categorías de los inmigrantes, ya que están contratados inicialmente en categorías profesionales bajas con escasas posibilidades de ascenso. Es precisamente aquí, en estos segmentos 
de baja cualificación, donde se han producido las mayores vacantes de empleo en el mercado laboral. El aumento de las vacantes de empleo tiene tres causas: demográficas, económicas y educativas.

Primero, las causas demográficas estriban en la reducción progresiva de las cohortes generacionales que vienen entrando en el mercado laboral desde el periodo 1986-1990, como consecuencia de la reducción de la natalidad en periodos anteriores. Segundo, las causas económicas estriban en las fuertes reconversiones industriales de 1979-1985 y de 1991-1994, que han servido para jubilar a aquellos trabajadores con cualificaciones bajas y niveles menores de estudio. Y, tercero, las causas educativas estriban en el aumento del nivel académico de las cohortes generacionales que vienen entrando en el mercado laboral desde 1976-1980. En consecuencia, todo ello ha venido dejando vacantes determinados nichos de empleo de baja cualificación, que, posteriormente, han ido ocupando progresivamente la inmigración, atraída por un ciclo económico alcista (1994-2007) impulsado por la construcción, el turismo y el consumo (Garrido, 2004).

Los principales flujos migratorios han sido de marroquíes, peruanos y ecuatorianos y rumanos. La inmigración marroquí y la peruana son las más antiguas, desde finales de los años ochenta. El resto es más reciente y concentrado en el periodo de 1999 a 2007. Los flujos de inmigración han sido tanto regulares como irregulares. La inserción en el empleo tiene ciertas limitaciones, como es, por ejemplo, a través de la entrada regulada de contingentes de inmigrantes para cubrir determinados nichos del mercado laboral. La política de control a través de contingentes no parece haber tenido éxito en España (Miguélez et al., 2009). Después de un año en el puesto de trabajo, la inmigración tiene libertad de movilidad geográfica y de elección. La forma dominante de inserción se realiza a través de la contratación temporal, hecho similar al de los autóctonos. En general, España recluta mano de obra poco cualificada. Según el World Bank, sólo el 2,6\% de los inmigrantes que trabajan en el sector terciario están cualificados con estudios universitarios.

\section{Metodología usada}

Este estudio se basa en el análisis de la MCVL del 2007, último año disponible en el momento de realizar la presente investigación. La MCVL representa a todos los inscritos en la Seguridad Social, unos diecinueve millones de trabajadores afiliados. La muestra consta de 1,2 millones de personas, de las cuales hemos analizado 713.660, lo que implica un bajo error muestral de $+/-0,09 \%$. Los datos están originalmente pensados como datos registrales, razón por la cual hay que realizar una operación previa de depuración para homogeneizar los datos y construir las variables y operacionalizar los conceptos analíticos ${ }^{6}$.

6. La muestra es de 1.200 .998 personas en relación con una población de referencia de 30.024.950. Si consideramos un nivel de confianza del 95,5\% en el supuesto de una estimación porcentual asumiendo que $\mathrm{P}=\mathrm{Q}=50 \%$, arroja un error de sólo el 0,09\%. 
La muestra se ha diseñado tomando como población de referencia una definición amplia: «todas las personas que han estado en situación de afiliado en alta, o recibiendo alguna pensión contributiva de la Seguridad Social en algún momento del año de referencia» (MTIN, 2007: 3). Desde el punto de vista del ámbito temporal, se consideran a todos los individuos que han estado en relación con la Seguridad Social en algún momento del año, no en una fecha fija, para facilitar así la presencia en la muestra de personas que trabajan regularmente, pero que entran y salen de manera continuada de una situación de alta laboral.

Las variables que hemos analizados son las siguientes: sexo, edad, nivel de estudios, origen, categoría laboral, grupos de cotización a la Seguridad Social, tipo de contrato laboral, seguridad en el empleo, duración del contrato, antigüedad en el mercado de trabajo, movilidad, tamaño de la empresa, sector de actividad y lugar de residencia. El periodo de análisis abarca desde 1967 hasta 2007 y los individuos de la muestra son los mismos siguiendo una clasificación de tipo panel.

El concepto de categoría laboral ha sido construido a partir de los grupos de cotización del registro de la Seguridad Social. Por tanto, el grupo de cotización es el equivalente funcional de la noción de categoría ${ }^{7}$, más comúnmente utilizada en sociología. Los grupos de cotización de la Seguridad Social son los diez colectivos que aparecen en la tabla 1 . Así pues, según los datos de la MCVL, las categorías profesionales más numerosas son las más bajas, lo que ya de por sí da cuenta de la estructura económica del país. Las categorías de peones, oficiales de tercera y segunda, personal auxiliar y subalterno representan el $70 \%$ de los trabajadores registrados en la MCVL. Los inmigrantes están sobrerrepresentados en las tres categorías más bajas; mientras que las categorías más altas, que implican requisitos de estudios universitarios, representan un $11 \%$ del total.

Por grandes categorías profesionales, los directivos, los cuadros y los mandos intermedios son, en su mayoría, autóctonos, mientras que los inmigrantes son pocos en esta categoría. El personal de administración y servicios es también, en su mayoría, autóctono, mientras que los inmigrantes son notablemente menos.

El modo de construir el concepto de movilidad vertical ascendente ha consistido en tomar como referencia el primer contrato laboral y analizar los cambios de categorías ascendentes o descendentes, a lo largo de los diez grupos señalados. Cabe advertir al lector del «efecto suelo y del efecto techo" usado en esta literatura (Garrido, 2004; Miret et al., 2008). Es decir, aquellos que entran en su primer contrato en la categoría más alta no pueden ascender más, por consiguiente, aparecerían como inmóviles (pero son poco significativos). Lo mismo ocurre con el efecto «suelo».

7. Las categorías de clasificación de la Seguridad Social tomadas como indicador pueden tener algunas insuficiencias, puesto que bastantes trabajadores son registrados en la Seguridad Social en una categoría más baja que la correspondiente al trabajo que realmente desempeñan. 
Tabla 1. Distribución de la población asalariada dada de alta en la seguridad social según grupo de cotización

\begin{tabular}{lrrrr}
\hline & Autóctonos & Inmigrantes & Diferencia & Total \\
\hline Ingenieros, licenciados, alta dirección & $8,0 \%$ & $4,2 \%$ & $+3,8$ & 6,0 \\
Ingenieros técnicos, ayudantes titulados & $6,7 \%$ & $2,0 \%$ & $+4,8$ & 5,0 \\
Jefes administrativos y de taller & $4,9 \%$ & $2,1 \%$ & $+2,7$ & 4,2 \\
Ayudantes no titulados & $3,8 \%$ & $2,0 \%$ & $+1,8$ & 3,3 \\
Oficiales administrativos & $13,2 \%$ & $6,8 \%$ & 6,4 & 10,5 \\
Subalternos & $4,4 \%$ & $3,3 \%$ & $+1,1$ & 4,3 \\
Auxiliares administrativos & $13,8 \%$ & $9,9 \%$ & $+3,9$ & 11,6 \\
Oficiales $1 .^{\mathrm{a}}$ y 2. & $19,7 \%$ & $22,8 \%$ & $-3,1$ & 20,1 \\
Oficiales 3. y especialistas $^{\text {Pand }}$ & $10,4 \%$ & $17,2 \%$ & $-6,8$ & 12,2 \\
Peones y menores & $15,2 \%$ & $29,8 \%$ & $-14,6$ & 22,8 \\
Total & $100,0 \%$ & $100,0 \%$ & & 100,0 \\
\hline
\end{tabular}

Fuente: elaboración propia con datos de la MCVL (2007).

Una de las variables usadas para explicar la movilidad vertical es el indicador sintético seguridad en el empleo. Éste ha sido construido a partir de clasificar a los asalariados en tres grupos:

a) Aquellos que tienen una seguridad baja: asalariados con más del 50\% de sus contratos temporales a lo largo de su trayectoria laboral.

b) Aquellos que tienen seguridad media: asalariados que han tenido entre el 50 y el $80 \%$ de sus contratos estables.

c) Aquellos que tienen seguridad alta: asalariados que han tenido más del $80 \%$ de sus contratos estables.

La selección realizada de los grupos de inmigrantes por origen nacional estriban en un criterio numérico, los más numerosos: marroquíes y peruanos, que, además, constituyen la inmigración más antigua, seguidos de ecuatorianos y rumanos, así como del resto de Europa y del resto del mundo.

En la siguiente sección I, estudiaremos el ascenso de los inmigrantes a los salarios altos, esto es, la hipótesis de la asimilación ocupacional. En este sentido, tomamos la cotización de los trabajadores a la Seguridad Social como equivalente funcional de los salarios. Las cotizaciones han sido divididas en cinco quintiles salariales. Otro indicador es la diferencia salarial construida a partir de la media salarial considerada como un indicador igual a 100. En esta sección, contestaremos a la cuestión sobre cuáles son las variables independientes que explican el ascenso a los salarios altos, para ello, hemos realizado análisis bivariados, tablas de contingencia y una regresión logística multinomial.

En la sección III, examinaremos la movilidad laboral vertical considerada entre la categoría profesional del primer contrato de inserción en el mercado laboral y la última categoría del contrato actual. Por tanto, ello nos permite ver 
la población asalariada que cambia de posición en la escala de las diez categorías profesionales registradas en la Seguridad Social. Los movimientos verticales los clasificamos de la siguiente manera:

a) Descendentes.

b) Inmóviles, es decir, mantienen la misma categoría que el contrato inicial.

c) Ascendente baja, cambia de una a dos posiciones en la escala.

d) Ascendente media, de tres a cinco posiciones.

e) Ascendente alta, cambia de seis a nueve posiciones.

Este indicador nos proporciona información sobre la población asalariada afectada por la movilidad laboral vertical y nos permite ver las diferencias entre autóctonos e inmigrantes. Para esta sección, hemos realizado un análisis factorial de correspondencias múltiples en combinación con un análisis de clasificación que nos ha permitido obtener una tipología de las distintas trayectorias laborales, desde la primera hasta la última categoría laboral desempeñada por los individuos.

\section{Seccion II. Análisis de la asimilación ocupacional y salarial}

La distribución de la población según quintiles salariales pone de relieve que los inmigrantes ocupan el nivel más bajo (primer quintil) en mayor proporción que los nativos. Especialmente la proporción de mujeres inmigrantes en dicho quintil es mayor que la de hombres. Por el contrario, en el quintil salarial más alto, la mayor participación la tienen los hombres autóctonos. Los inmigrantes son notoriamente pocos (tabla 2).

Como ya hemos señalado, uno de los debates centrales en el estudio de la movilidad ocupacional de la inmigración es la hipótesis de la convergencia salarial o asimilación ocupacional de la inmigración a lo largo del tiempo. En líneas generales, se produce una convergencia salarial entre autóctonos e inmigrantes a lo largo del tiempo (grafica 1). Los inmigrantes inician su trayectoria, en los dos primeros años, con salarios bajos, pero superiores a los de los autóctonos. Ello se explica porque los autóctonos suelen ser jóvenes que compatibilizan

Tabla 2. Distribución de la población asalariada en quintiles

\begin{tabular}{|c|c|c|c|c|}
\hline & \multicolumn{2}{|c|}{ Autóctono } & \multicolumn{2}{|c|}{ Inmigrante } \\
\hline & 1 Varón & 2 Mujer & 1 Varón & 2 Mujer \\
\hline 1. ${ }^{\text {er }}$ quintil. Salarios muy bajos & $11,90 \%$ & $28,30 \%$ & $30,30 \%$ & $52,70 \%$ \\
\hline 2. ${ }^{\circ}$ quintil. Salarios medio-bajos & $5,80 \%$ & $10,90 \%$ & $11,70 \%$ & $13,90 \%$ \\
\hline $3 .^{\text {er }}$ quintil. Salarios medios & $23,90 \%$ & $20,90 \%$ & $31,20 \%$ & $18,90 \%$ \\
\hline $4^{\circ}{ }^{\text {quintil. Salarios medio-altos }}$ & $26,60 \%$ & $20,50 \%$ & $17,80 \%$ & $8,80 \%$ \\
\hline $5 .^{\circ}$ quintil. Salarios altos & $31,70 \%$ & $19,30 \%$ & $8,80 \%$ & $5,70 \%$ \\
\hline Total & $100,00 \%$ & $100,00 \%$ & $100,00 \%$ & $100,00 \%$ \\
\hline
\end{tabular}

Fuente: elaboración propia con datos de la MCVL (2007). 
Gráfica 1. Trayectoria salarial media según antigüedad en el mercado laboral. Salario medio $=100$

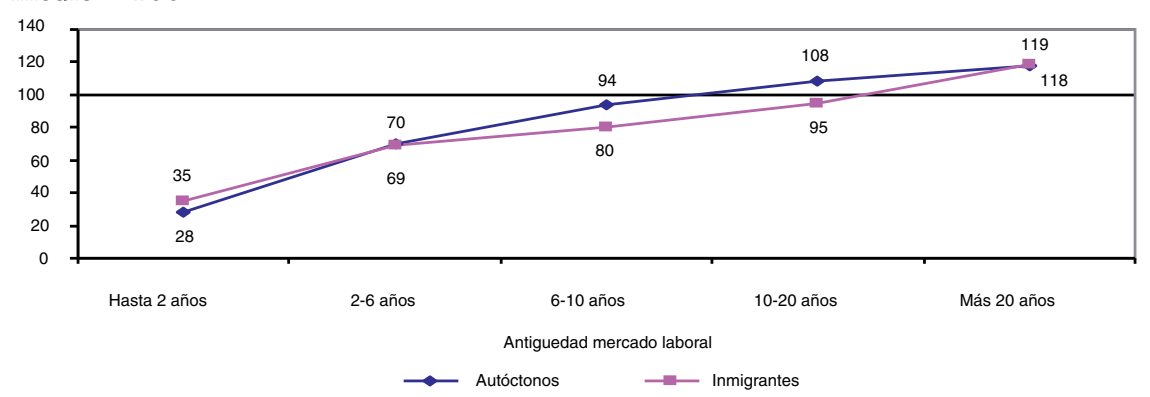

Fuente: elaboración propia con datos de la MCVL (2007).

estudio y trabajo, o bien tienen contratos de breve duración y porque trabajan en determinados periodos del año. No ocurre así en el caso de los inmigrantes. Éstos se insertan en los dos primeros años con edades superiores a la de los autóctonos y tienen más tiempo de dedicación al trabajo que los autóctonos. A continuación, entre los dos y los seis años de antigüedad, no se registran diferencias salariales, pero en el tercer momento, entre los seis y los diez años y entre los diez y los veinte años, se abre la brecha salarial entre autóctonos e inmigrantes. Ello de nuevo contribuye a explicar la idea de las trayectorias retardadas (lo que se refleja ahora en los salarios) para determinados grupos de inmigrantes con un nivel alto de estudios. Y, finalmente, vuelven a converger los salarios cuando la antigüedad es de más de veinte años.

\section{¿Que factores contribuyen a explicar el acceso a los salarios altos?}

En las páginas siguientes, examinamos cuáles son las variables explicativas que conducen a alcanzar los mayores niveles salariales. En particular, nos centraremos en el quintil salarial más alto. En la tabla 3, aportamos una regresión logística multinomial con la cual examinaremos dos modelos, uno para el conjunto de la población asalariada y otro para los inmigrantes. Obsérvese que el ajuste de los coeficientes de determinación en ambos modelos es relativamente alto, lo que pone de relieve la capacidad explicativa de los modelos. En el modelo 1, el pseudo $\mathrm{R}$ valor cuadrado explica el 54\% de la variabilidad y, en el modelo 2, explica el $48 \%$ de la variabilidad.

Las variables que más influyen en la explicación del acceso a los salarios altos son, por orden de importancia, las siguientes:

En primer lugar, la antigüedad, tanto para la población asalariada como para los inmigrantes. Para aquellos que llevan menos de dos años en el mercado de trabajo, las probabilidades de acceder al salario más alto disminuyen en un $99 \%$ en relación con aquellos que llevan más de veinte años, tomada ésta última como categoría de referencia. Esto es válido tanto para la población en general como para los inmigrantes. Quizás la alta influencia de esta variable 
Tabla 3. Variable dependiente: salarios altos, quinto quintil

\begin{tabular}{|c|c|c|c|c|c|c|c|c|}
\hline \multirow[b]{2}{*}{ Variables independientes } & \multicolumn{4}{|c|}{ Modelo 1. Población asalariada } & \multicolumn{4}{|c|}{ Modelo 2. Población inmigrante } \\
\hline & B & Error típico & $\operatorname{Exp}(B)$ & Sig. & B & Error típico & $\operatorname{Exp}(B)$ & Sig. \\
\hline Intersección & 3,545 & 0,059 & & ** & 3,307 & 0,187 & & \\
\hline Hombre & 2,130 & 0,015 & 8,419 & ** & 1,927 & 0,05 & 6,869 & ** \\
\hline Mujer $\left(^{*}\right)$ & 0 & - & - & - & 0 & - & - & ** \\
\hline 16-24 años & $-2,054$ & 0,053 & 0,128 & ** & $-1,448$ & 0,208 & 0,235 & - \\
\hline 25-34 años & $-0,055$ & 0,031 & 0,946 & ns & 0,347 & 0,104 & 1,415 & ** \\
\hline 35-44 años & $-0,041$ & 0,026 & 0,96 & $\mathrm{~ns}$ & 0,489 & 0,099 & 1,631 & ns \\
\hline 45-54 años & 0,111 & 0,025 & 1,118 & ** & 0,324 & 0,104 & 1,383 & ** \\
\hline Más 54 años $(*)$ & 0 & - & - & - & 0 & - & - & ** \\
\hline Estudios primarios & $-3,57$ & 0,034 & 0,028 & ** & $-2,894$ & 0,086 & 0,055 & - \\
\hline Estudios secundarios & $-3,009$ & 0,032 & 0,049 & $* *$ & $-2,493$ & 0,079 & 0,083 & ** \\
\hline Bachiller-FP & $-1,305$ & 0,031 & 0,271 & $* *$ & $-1,108$ & 0,071 & 0,33 & ** \\
\hline Universitarios $\left({ }^{*}\right)$ & 0 & - & - & - & 0 & - & - & ** \\
\hline Antigüedad hast & $-4,857$ & 0,109 & 0,008 & ** & $-5,368$ & 0,166 & 0,005 & - \\
\hline Antigüedad de 2 a 6 años & $-1,214$ & 0,034 & 0,297 & ** & $-2,091$ & 0,09 & 0,124 & ** \\
\hline ntigüedad de 6 a 10 años & $-0,548$ & 0,028 & 0,578 & ** & $-1,316$ & 0,09 & 0,268 & ** \\
\hline ntigüedad de 10 a 20 años & $-0,209$ & 0,021 & 0,811 & ** & $-0,638$ & 0,09 & 0,528 & ** \\
\hline dad de +20 años $(*)$ & 0 & - & - & - & 0 & - & - & ** \\
\hline Autóctono & 0,608 & 0,026 & 1,837 & ** & & & & \\
\hline Inmigrante $\left({ }^{*}\right)$ & 0 & - & - & - & & & & \\
\hline Desci & $-2,994$ & 0,035 & 0,05 & ** & $-2,614$ & 0,132 & 0,073 & ** \\
\hline Inmóvil & $-2,186$ & 0,031 & 0,112 & ** & $-1,895$ & 0,12 & 0,15 & ** \\
\hline Iscendencia baja & $-1,756$ & 0,032 & 0,173 & $* *$ & $-1,722$ & 0,123 & 0,179 & ** \\
\hline Ascendenci & $-1,552$ & 0,032 & 0,212 & ** & $-1,731$ & 0,128 & 0,177 & ** \\
\hline Ascen & 0 & - & - & - & 0 & - & - & - \\
\hline Seguridad baja & $-1,452$ & 0,021 & 0,234 & ** & $-1,252$ & 0,074 & 0,286 & ** \\
\hline Seguridad media & $-1,077$ & 0,017 & 0,341 & ** & $-1,054$ & 0,058 & 0,349 & ** \\
\hline d alta $(*)$ & 0 & - & - & - & 0 & - & - & - \\
\hline ura & $-2,634$ & 0,064 & 0,072 & ** & $-3,559$ & 0,332 & 0,028 & ** \\
\hline ndustria & 1,549 & 0,024 & 4,706 & $* *$ & 1,502 & 0,079 & 4,493 & ** \\
\hline Construcción & 1,863 & 0,028 & 6,446 & $* *$ & 1,599 & 0,083 & 4,946 & $* *$ \\
\hline Comer & $-0,023$ & 0,022 & 0,978 & $\mathrm{~ns}$ & $-0,089$ & ,073 & 0,915 & ns \\
\hline Hostelería & $-1,196$ & 0,037 & 0,302 & $* *$ & $-1,286$ & 0,107 & 0,276 & ** \\
\hline Transporte & 1,082 & 0,032 & 2,95 & ** & 0,886 & 0,097 & 2,425 & ** \\
\hline Educación & 0,555 & 0,032 & 1,742 & ** & 0,237 & 0,12 & 1,267 & * \\
\hline Banca & 2,144 & 0,04 & 8,537 & ** & 1,782 & 0,121 & 5,929 & ** \\
\hline A.PP. & 0,896 & 0,035 & 2,45 & ** & 0,806 & 0,172 & 2,238 & ** \\
\hline Hogares & $-1,046$ & 0,068 & 0,351 & $* *$ & $-1,355$ & 0,271 & 0,258 & ** \\
\hline Sanidad & 1,053 & 0,028 & 2,866 & ** & 0,994 & 0,094 & 2,701 & ** \\
\hline Otras actividades $\left({ }^{*}\right)$ & 0 & - & - & - & 0 & - & - & - \\
\hline Contrato indefinido & 1,749 & 0,019 & 5,746 & $* *$ & 1,393 & 0,068 & 4,027 & ** \\
\hline Contrato temporal $\left({ }^{*}\right)$ & 0 & - & - & - & 0 & - & - & - \\
\hline De 1 a 6 trabajadores & $-3,166$ & 0,023 & 0,042 & ** & $-2,711$ & 0,077 & 0,067 & ** \\
\hline & $-1,854$ & 0,025 & 0,157 & $* *$ & $-1,428$ & 0,08 & 0,24 & ** \\
\hline De 26 a 50 traba & $-1,290$ & 0,026 & 0,275 & $* *$ & $-0,913$ & 0,083 & 0,401 & ** \\
\hline De 51 a 100 trabajadores & $-0,929$ & 0,026 & 0,395 & ** & $-0,574$ & 0,086 & 0,563 & ** \\
\hline De 101 a 250 trab & $-0,647$ & 0,025 & 0,523 & ** & $-0,076$ & 0,08 & 0,927 & $\mathrm{~ns}$ \\
\hline De 251 a 500 trabajadores & $-0,445$ & 0,028 & 0,641 & $* *$ & $-0,073$ & 0,093 & 0,929 & $\mathrm{~ns}$ \\
\hline Más de 500 trabajadores $\left(^{*}\right)$ & 0 & - & - & - & 0 & - & - & - \\
\hline Número de casos & & & & 3.358 & & & & .065 \\
\hline$-2 \log$ verosimilitud & & & & .976 & & & & 361 \\
\hline & & 317 & 934 (ns, 0 & 000) & & & 430 (ns, 0 , & 000) \\
\hline Pseudo R² de Nagelkerke & & & &, 544 & & & &, 483 \\
\hline $\begin{array}{l}\left.{ }^{*}\right) \text { Categoría de referencia } \\
{ }^{* *} \text { Coeficiente significativo } \\
\end{array}$ & & & & $\mathrm{Co}$ & te sig & $\begin{array}{l}\text { ivo al } 5 \% \text {. } \\
\text { ificativo. }\end{array}$ & & \\
\hline
\end{tabular}

Fuente: Elaboración propia basada en la MCVL. 
estribe en que los datos de la MCVL proporcionan información a partir de lo que, en algunos estudios de movilidad, se ha llamado "madurez laboral», pero, en todo caso, también concuerda con los hallazgos encontrados en otros estudios. Por ejemplo, Green (1999) señala una antigüedad de diez años para los inmigrantes en Canadá. Kogan (2003) y Dickens y McKnight (2009) ${ }^{8}$ hablan de veinte años de antigüedad en los casos de Alemania y Reino Unido, respectivamente. Por el contrario, nuestro hallazgo difiere del encontrado por Izquierdo et al. (2009), que habla de una rápida «asimilación salarial» de los inmigrantes legales en el plazo de cinco a seis años, aunque las diferencias con los autóctonos no desaparecen con el tiempo.

En segundo lugar, el nivel de estudios tiene también una importante influencia en el acceso a los salarios altos. Para quienes tienen estudios primarios, disminuyen las probabilidades de promoción a los salarios altos en un $97 \%$, en comparación con aquellos que tienen estudios universitarios. Lo mismo ocurre con los inmigrantes, sólo que el peso que tiene la categoría de universitarios es menor que la que tiene para el conjunto de los asalariados. Obsérvese también que quienes poseen estudios de bachillerato y FP también tienen muchas probabilidades de acceder a salarios altos, ya sea el conjunto de asalariados como los inmigrantes. Sin embargo, si comparamos ambas poblaciones, se pone de relieve que los asalariados autóctonos tienen casi el doble de probabilidades de acceder a los salarios altos que los inmigrantes. Un hallazgo similar lo encontramos en el estudio de Coughlan (1998) realizado en Australia con la población vietnamita. Este investigador encuentra la importancia que tiene el nivel de estudios y, particularmente, el conocimiento de la lengua en la movilidad ascendente, aunque sólo un 19\% de los inmigrantes vietnamitas tiene movilidad ascendente. Izquierdo et al. (2009) también descubren que aquellos que poseen estudios primarios y estudios secundarios tienen menores probabilidades de acceder a los salarios altos que aquellos quienes tienen estudios altos.

Nótese que estas dos primeras variables, que indican características de los individuos, son las habitualmente usadas desde el enfoque teórico del capital humano. En este sentido, bastantes investigadores (McAllister, 1995; Tubergen, 2008 y otros) nos recuerdan que ninguna de las variables individuales es determinante por sí sola y sin contextualizar. Este es precisamente el hallazgo que encontramos en la tercera variable: la empresa como variable explicativa importante.

La tercera variable de más importancia es el tamaño de empresa, es decir, una variable estructural más utilizada por el enfoque de las teorías de la segmentación. Así, para aquellos que trabajan en empresas pequeñas, de menos de seis empleados, disminuyen las probabilidades de acceder a los

8. Estos investigadores señalan que los inmigrantes masculinos británicos tardan unos veinte años en alcanzar las cotas salariales de los nacidos en el Reino Unido. Sin embargo, la inmigración no es homogénea. La asimilación de la población europea se produce antes que la de aquellos procedentes de África o de Asia, como veremos más adelante. 
salarios altos en comparación con aquellos que trabajan en empresas de más de quinientos empleados. A medida que aumenta el tamaño de la empresa, aumentan las probabilidades de acceder a los salarios altos. Esta pauta se sigue también para los inmigrantes, aunque éstos últimos tienen menos probabilidades de acceder a los salarios altos. En efecto, en general, podemos decir que, para aquellos que trabajan en las grandes empresas, hay más probabilidades de acceder a los salarios altos de forma inversa que para aquellos que trabajan en empresas pequeñas. Esto es así porque las grandes empresas tienen precisamente amplios organigramas jerárquicos que posibilitan las carreras profesionales, como ha señalado Osterman (1985) en un estudio sobre los mercados internos de trabajo. Sin embargo, dado el alto volumen de pequeñas empresas en España, las probabilidades de desarrollar carreras profesionales están bastante limitadas para los autóctonos y aún más para los inmigrantes, a tenor de que este tipo de empresas tienen organigramas con muy pocas escalas jerárquicas.

En cuarto lugar, la variable de movilidad vertical de categoría profesional contribuye a explicar quienes llegan a los salarios altos. Para aquellos que descienden de categoría, disminuyen las probabilidades de acceder a los salarios altos en un 95\%. Para aquellos que están en situación de inmóviles, también disminuyen las probabilidades de acceder a los salarios altos en un $89 \%$. Véase que, a medida que la ascendencia de categoría profesional es mayor, aumentan lógicamente las probabilidades de acceder a los salarios altos. La misma pauta se sigue para los inmigrantes, aunque estos tienen menos probabilidades de acceder a los salarios altos.

En quinto lugar, otra variable influyente es el género. Para los hombres, la probabilidad de acceder a los salarios altos se multiplica por ocho en relación con las mujeres. Y para los hombres inmigrantes también se multiplica por seis la probabilidad de acceder al quinto quintil salarial. Estos datos nos indican probablemente el problema del «techo de cristal» para las mujeres: estas tienen dificultades para acceder a los salarios altos y a las categorías profesionales altas, a tenor de la segregación de género en el mercado de trabajo y del reparto laboral reproductivo desigual, lo que lastra el desarrollo de las carreras profesionales de las mujeres (Carrasquer et al., 2007).

En sexto lugar, el sector de actividad tiene también una importante capacidad explicativa en las trayectorias salariales. Es una variable estructural. En los sectores de banca y seguros, construcción, industria, sanidad y Administración pública se ofrecen más probabilidades, tanto para autóctonos como para inmigrantes, de acceder a los salarios altos en comparación con el sector de "otras actividades», tomada ésta como categoría de referencia. Por el contrario, hay otros sectores de actividad que se sitúan en el extremo opuesto: apenas ofrecen probabilidades de acceder a los salarios altos. Estos sectores son: agricultura, hogares y servicio doméstico y hostelería. Es decir, justamente los sectores donde hay mayor proporción y concentración de inmigrantes, lo que nos indica que los inmigrantes se distribuyen en los sectores de salarios bajos, como ya hemos visto en capítulos precedentes. 
En séptimo lugar, la variable edad tiene también cierto poder explicativo en el acceso a los salarios altos. Los más jóvenes, entre dieciséis y veinticuatro años, tienen un $87 \%$ menos de probabilidades de acceder a los salarios altos que aquellos que tienen más de cincuenta y cuatro años. Sin embargo, la edad no ofrece mucha más capacidad explicativa, por cuanto el resto de las cohortes tienen una pauta muy parecida, incluso tanto para autóctonos como para inmigrantes. Dicho de otra forma, las cohortes de edad superiores al grupo de veinticuatro a treinta y cuatro años, incluida ésta, pueden alcanzar salarios altos. Por consiguiente, la edad sólo es discriminante con la cohorte más joven, comprendida entre los dieciséis y los veinticuatro años.

Por último, aquellos asalariados que poseen contratos de trabajo estable tienen cinco veces más de posibilidades de acceder a los salarios altos que aquellos que han tenido contratos temporales. La pauta es igual para los inmigrantes, pero con la diferencia de que estos tienen menos probabilidades de ascender que los autóctonos. Esta variable arroja resultados parecidos a los que nos proporciona la variable "proxy" seguridad en el empleo. La seguridad en el empleo explica que aquellos que han tenido seguridad baja en el empleo, con más del $50 \%$ de sus contratos temporales a lo largo de su trayectoria laboral, tienen disminuidas sus probabilidades de alcanzar un salario alto un $77 \%$ en relación con aquellos que han tenido una seguridad alta en el empleo. No hay diferencias significativas entre autóctonos e inmigrantes a este respecto.

En resumen, podemos hacer tres consideraciones. La primera, si medimos la trayectoria laboral más alta en función del indicador de salarios, el resultado estará ordenado jerárquicamente según la importancia de las variables más influyentes, que son: la antigüedad, los estudios universitarios, el tamaño de la empresa, la movilidad laboral ascendente, el género, el tipo de contrato laboral, la seguridad en el empleo durante toda la trayectoria laboral, los sectores de banca y seguros, la construcción, la Administración pública y la sanidad y la edad. La segunda consideración es que los autóctonos y los inmigrantes tienen las mismas pautas para explicar el hecho de cómo se llega a los salarios superiores. Sin embargo, ambos grupos difieren en las probabilidades: los autóctonos tienen más probabilidades de acceder a los salarios altos que los inmigrantes en cada una de las categorías examinadas. Y la tercera consideración, observada a lo largo de estas páginas, es la interacción de las variables referidas a las caracteristicas de los individuos, como son el nivel de estudios, la antigüedad y el género, con otras variables de carácter estructural, como son el tamaño de la empresa y el sector de actividad. Ello quiere decir que las variables individuales, típicamente utilizadas por el enfoque teórico del capital humano y las variables estructurales, utilizadas por la teoría de la segmentación, son complementarias entre sí. O sea, ambos enfoques teóricos se complementan entre sí, ya que nos ofrecen explicaciones desde el lado de la oferta y de la demanda del mercado de trabajo. 


\section{Sección III. Análisis de la segmentación}

A través de un uso conjunto del análisis de correspondencias y del análisis de clasificación (López-Roldán, 1996a, 1996b; Domínguez y López, 1996) ${ }^{9}$, hemos establecido distintos tipos de movilidad ocupacional ascendente que han seguido los individuos estudiados. Con el análisis de correspondencias, se obtienen dos factores principales de diferenciación.

Por un lado, con el 54\% de variancia total, se configura un factor de segmentación laboral que marca las posiciones jerarquizadas en el mercado de trabajo, resultado de trayectorias cortas e inestables frente a trayectorias prolongadas y de estabilización. Son perfiles y asociaciones predominantes, tendencias que ilustran un continuo que pasa también por situaciones intermedias o mixtas, y que, de forma principal, se expresan en una dimensión de dinámica segmentadora. Las características de la oferta se pueden relacionar y observar en esta dimensión (gráfico 2) para constatar cómo el origen inmigrante, de manera predominante, se vincula con el extremo de debilidad laboral, como también lo hacen la juventud y el menor nivel de estudios; las jornadas parciales son igualmente propias de esta polaridad, pero apenas discriminan entre hombres y mujeres.

Por otro lado, el segundo factor, de menor importancia que el primero, ya que concentra solamente el $22 \%$ de la varianza, diferencia algunas de las especificidades que acabamos de describir del polo de debilidad laboral. Lo podemos calificar de contraposición entre la precariedad laboral y las posiciones intermedias, es decir, entre un perfil predominante marcado por el hecho de ser trabajador de la agricultura y de hogares y servicios, con mínima cualificación, donde no se produce la promoción laboral, frente a niveles de categoría laboral de oficiales, con procesos de baja promoción, sobre todo en sectores como la construcción, la industria o el transporte. Aquí sí que adquiere mayor relevancia el sexo como perfil diferenciador y, vinculado a ello es, sobre todo, la

9. Con el ACM, es posible realizar el estudio simultáneo de las relaciones de asociación entre múltiples variables cualitativas o categóricas. El resultado de su aplicación es la obtención de unas nuevas variables, dimensiones o factores de diferenciación de los individuos que se generan por combinaciones (lineales) del conjunto original de variables cualitativas. El número de factores obtenidos es menor que el de variables originales, aun perdiendo una parte de la información inicial (expresada en términos de varianza o de inercia), pero ganando en significación y parsimonia. Además, estos factores se caracterizan por estar ordenados jerárquicamente por su importancia (valores propios) como factores de diferenciación de los individuos, y entre ellos son (linealmente) independientes. La técnica de clasificación automática utilizada es un algoritmo mixto que aplica un triple proceso clasificatorio: una primera clasificación se obtiene por el cruce de varias particiones de base construidas alrededor de centros móviles; las clases estables que se obtienen de este primer procedimiento se agregan a continuación por un método de clasificación jerárquica ascendente, según el criterio de Ward o de mínima pérdida de inercia, y, finalmente, las diferentes particiones de los individuos que se pueden obtener a partir del árbol de agregación del procedimiento Ward optimizan o se consolidan mediante una reasignación a los diferentes grupos creados en cada partición con un nuevo proceso de clasificación por centros móviles que mejora la inercia entre los grupos. Los análisis se han realizado con el programa estadístico SPAD. 
ocupación en los sectores donde se cotiza en el régimen agrario o de empleados del hogar el elemento más diferenciador.

Con el análisis de clasificación, hemos establecido cinco tipos de movilidad ocupacional vertical, lo que sintoniza con las explicaciones proporcionadas desde la teoría de la segmentación. Son los que exponemos a continuación.

\section{Tipo 1: alta movilidad ocupacional ascendente}

El tipo 1 (un 20\%) recoge a los trabajadores con mayor categoría laboral, nivel de ingresos, estabilidad y antigüedad en el mercado de trabajo, que les ha permitido gozar de una importante movilidad ocupacional ascendente en el tiempo. Es el grupo de mayor éxito. Nótese aquí el peso que tienen las variables estructurales, como son las grandes y medianas empresas, así como los sectores de banca y seguros, las administraciones públicas, sanidad y educación. Es decir, sectores que reclutan de entrada a individuos con titulaciones universitarias. En consecuencia, se corresponden con los trabajadores que poseen mayores niveles de estudios, de más de treinta y cinco años y autóctonos. La población inmigrante sólo está presente en un $4 \%$, nueve puntos menos que el conjunto.

Los inmigrantes cuyas trayectorias están clasificadas en el tipo 1 son pocos. Según el origen, el grupo más importante de inmigrantes es, proporcionalmente, el de los ciudadanos de la UE-15, seguido a notable distancia de los peruanos y después por los marroquíes. La presencia de inmigrantes de otros orígenes en este tipo 1 es insignificante (véase tabla 4).

El perfil de los ciudadanos de la UE-15 que están en este primer tipo son personas cualificadas, como ingenieros, licenciados e ingenieros técnicos y jefes administrativos y de taller, que trabajan y empresas grandes de más de 250 trabajadores. De hecho, más de la mitad de ellos está en estas tres categorías profesionales, ha tenido contratos estables y ha trabajado en otras actividades (un 22\%), educación (un 16\%), industria (un 13\%), banca y seguros (un $11 \%$ ) y sanidad (un 10\%). La trayectoria de los ciudadanos de la UE-15 hasta alcanzar el primer tipo es notablemente más corta que la de otros grupos de origen: el 39\% de ellos tarda menos de diez años, lo que se puede calificar como

Tabla 4. Distribución de la población inmigrante y autóctona según los tipos de movilidad ocupacional ascendente

\begin{tabular}{lrrrrrc}
\hline & Tipo 1 & Tipo 2 & Tipo 3 & Tipo 4 & Tipo 5 & Total \\
\hline Españoles & $22,3 \%$ & $29,5 \%$ & $19,9 \%$ & $20,7 \%$ & $7,6 \%$ & $100,0 \%$ \\
Marroquíes & $2,8 \%$ & $6,3 \%$ & $22,4 \%$ & $32,9 \%$ & $35,6 \%$ & $100,0 \%$ \\
Peruanos & $4,0 \%$ & $14,6 \%$ & $18,2 \%$ & $41,6 \%$ & $21,6 \%$ & $100,0 \%$ \\
Ecuatorianos & $0,8 \%$ & $7,7 \%$ & $24,1 \%$ & $39,0 \%$ & $28,3 \%$ & $100,0 \%$ \\
Rumanos & $0,4 \%$ & $4,3 \%$ & $23,1 \%$ & $35,3 \%$ & $36,9 \%$ & $100,0 \%$ \\
Resto UE & $15,0 \%$ & $23,1 \%$ & $18,2 \%$ & $32,4 \%$ & $11,3 \%$ & $100,0 \%$ \\
\hline
\end{tabular}

Fuente: elaboración propia con datos de la MCVL (2007). 
trayectoria rápida. Los peruanos que están en este primer tipo están situados en proporciones parecidas en las tres o cuatro categorías profesionales más altas, pero difieren de los ciudadanos de la UE-15, porque están ubicados en otros sectores de actividad. Por consiguiente, parecería como si se diera una inserción especializada y específica por origen en el mercado laboral.

En efecto, la mayoría de los peruanos, de este primer tipo, están colocados en la sanidad (un 48\%); en notable menor proporción, en otras actividades (un 19\%); en banca y seguros (un 6,7\%), así como en empresas grandes de más de 250 trabajadores. Nótese una vez más que las posibilidades de promoción están en las empresas grandes. Prueba de ello es que el $70 \%$ de los peruanos y de los marroquíes que han alcanzado el tipo 1 están empleados en esas empresas, pero los marroquíes que están también en este primer tipo se diferencian de los ciudadanos de la UE-15 y de los peruanos. Los marroquíes están empleados en la sanidad (un 25\%), aunque en menor proporción que los peruanos. También hay marroquíes en la industria (un 13\%) y en la educación (un 11\%). Los marroquíes tienen las trayectorias laborales más retardadas: el 76\% llegan a este tipo 1 después de más de veinte años en el mercado de trabajo. Indicativo de ello es también la edad. El 78\% de los marroquíes que está en el tipo 1 tiene más de cuarenta y cinco años.

En cambio, los peruanos llegan bastante antes, entre los diez y los veinte años (un 42\%) e incluso antes (un 20\%). Prueba de que promocionan antes es que el $60 \%$ de los peruanos que figuran en el tipo 1 están comprendidos entre los veinticinco y los cuarenta y cuatro años. Igualmente, los poquísimos rumanos y ecuatorianos que figuran en el tipo 1 son, en su mayoría (un 67\% y un 65\%, respectivamente), jóvenes comprendidos entre los veinticinco y los cuarenta y cuatro años. Estos datos nos sugieren, en el caso de los peruanos, los rumanos y los ecuatorianos, que se trata de personas con estudios universitarios y altos niveles de cualificación profesional. En efecto, los subgrupos dominantes según cada uno de los mencionados orígenes tienen estudios universitarios: el $42 \%$ de los peruanos, el $30 \%$ de los rumanos, el $26 \%$ de los marroquíes y el $22 \%$ de los ecuatorianos que están ubicados en el tipo 1 . Es más, son estos tres grupos de origen lo que tienen registrada una mayor movilidad laboral ascendente: el $45 \%$ de los peruanos y de los rumanos ha cambiado entre 3 y 9 posiciones en la escala de categorías profesionales, mientras que los ecuatorianos y los marroquíes lo han hecho en menor proporción (un 20\%).

En breve, la diferenciación en la inserción de los inmigrantes en sectores determinados de actividad de acuerdo con el origen, nos sugiere la idea de que éstos se movilizan siguiendo determinadas redes sociales que conectan el lugar de origen y la inserción laboral en un nicho del mercado, lo que concuerda con lo que se ha venido observando desde las teorías de la segmentación. La estratificación por origen tiene que ver con las características de las cadenas de movilidad y su inserción específica en las actividades, donde las redes sociales han echado raíces y han formado una masa crítica que permite realizar la acumulación del capital social necesario para favorecer la movilidad horizontal. 


\section{Tipo 2: movilidad ocupacional ascendente media}

El tipo 2 (un 27\%) recoge situaciones que también son de estabilidad laboral, con una movilidad ocupacional ascendente e igualmente dilatadas en el tiempo, que han supuesto promociones medias, de personas con grupos de cotización intermedios en la escala laboral, con niveles medios o altos de ingresos salariales. Son trabajadores de la industria y del comercio, sobre todo, ocupados en empresas de tamaño mediano. En este tipo predomina el nivel de estudios de bachiller o FP superior y las edades son intermedias. Los inmigrantes representan tan sólo el 6\%, lo que nos pone de relieve el problema de la limitación que tienen los inmigrantes en la movilidad ocupacional ascendente.

\section{Tipo 3: movilidad ocupacional baja}

El tipo 3 (un 20\%) se identifica mayoritariamente con los grupos de cotización de oficiales, manifiesta niveles bajos de promoción laboral y salarios mediobajos. Los niveles de temporalidad son destacables y alcanzan niveles bajos de estabilidad laboral a lo largo de unas vidas laborales más o menos dilatadas, pero de trabajadores insertados laboralmente con al menos seis años de antigüedad. Se trata de trabajadores de pequeñas empresas de la construcción y la industria, de la hostelería y el transporte. Son mayoritariamente varones con niveles educativos bajos, de edades intermedias. Aquí los inmigrantes se sitúan en el 13\% del conjunto del tipo.

\section{Tipo 4: movilidad ocupacional baja y categorías profesionales bajas}

El tipo 4 (un 23\%) se corresponde con el grupo de cotización de categoría inferior, donde predominan la temporalidad y las trayectorias de inseguridad laboral, la ausencia de promoción, los niveles bajos de salarios, en relación con un colectivo de trabajadores caracterizado por su menor antigüedad en el mercado de trabajo y ocupado en empresas pequeñas en sectores como la hostelería, el comercio, la construcción y los hogares y servicios.

Se trata, principalmente, de jóvenes de ambos sexos, pero con un predominio de mujeres con un nivel de estudios bajo. Aquí la población inmigrante alcanza el $22 \%$, lo que nos pone de relieve que, cuanta menos movilidad ocupacional ascendente se registre, mayor es la presencia de los inmigrantes. Los grupos de origen más numerosos son, por este orden: los peruanos, los ecuatorianos, los rumanos, los marroquíes y los ciudadanos de la UE-15.

\section{Tipo 5: con pocas posibilidades de promoción laboral}

El tipo 5 (un 10\%), por último, concentra un perfil de trabajador agrario y del sector de hogar y servicios, con la mínima categoría laboral, los más bajos niveles de ingresos y la mínima antigüedad en el mercado de trabajo, lo cual provoca la máxima inestabilidad laboral e imposibilita la promoción. Predominan 
Gráfico 1. Tipos de trayectorias y segmentación laboral

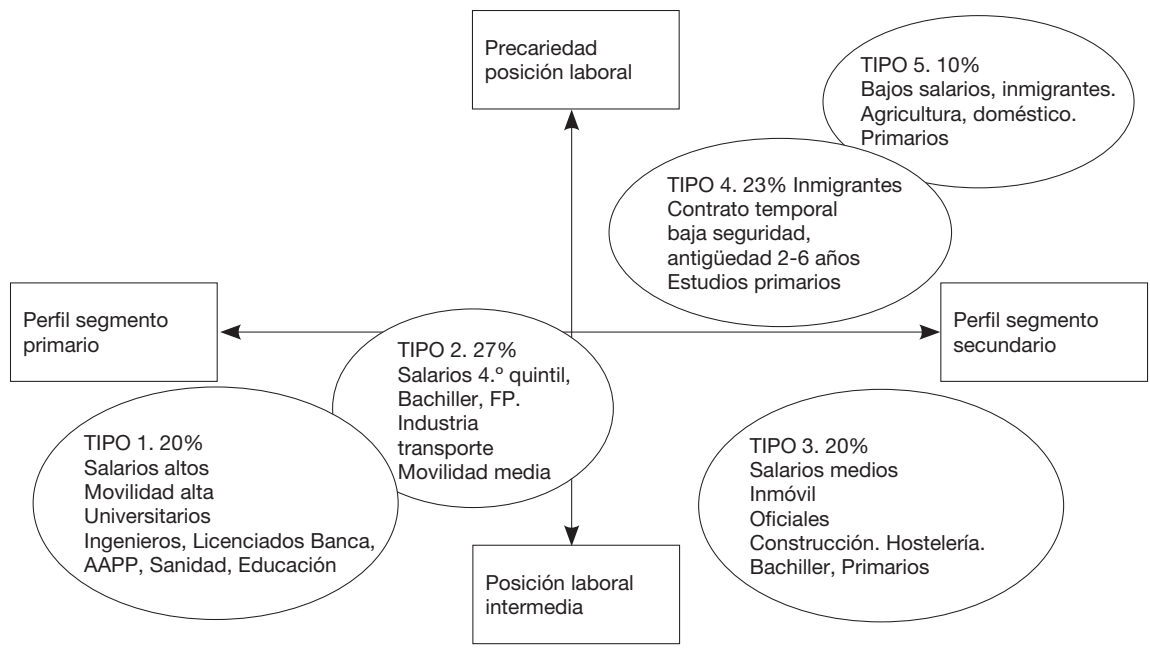

Fuente: elaboración propia con datos de la MCVL (2007).

aquí las personas jóvenes, las mujeres en mayor medida, con niveles educativos bajos y un 35\% de población inmigrante. Los inmigrantes tienen un 10\% más de probabilidades de pertenecer a este grupo que los trabajadores autóctonos ${ }^{10}$. Aquí tenemos un sentido de "asimilación ocupacional» de la inmigración, en términos de inmovilidad, de no cambio de categoría profesional.

Este quinto grupo está compuesto fundamentalmente por rumanos, seguidos de marroquíes, ecuatorianos y peruanos. El perfil dominante de esta categoría profesional es el de peón, con un nivel de estudios bajo. Ilustrativo de ello es que, en torno al 53\% de los marroquíes, seguidos de ecuatorianos (un 35\%) y rumanos (un 28\%), de este tipo sólo tienen estudios primarios. Trabajan en empresas pequeñas ${ }^{11}$ y muy pequeñas de la construcción y la agricultura, como se pone de relieve con el hecho de que el 72\% de los ecuatorianos, el 63\% de los rumanos y el $46 \%$ de los marroquíes ubicados en este quinto tipo trabaja en empresas de menos de cincuenta empleados, mientras que el porcentaje de autóctonos que están ocupados en dichas empresas es inferior (un 43\%).

Como hemos dicho antes, es la categoría de peón la que condiciona el quinto tipo y la que afecta a los inmigrantes en mayor proporción ${ }^{12}$. Se trata de trabajadores con salarios bajos, con pocas posibilidades de promoción profesional

10. Este tipo de análisis nos ha permitido representar gráficamente la asociación de las variables distinguiendo las variables activas, que caracterizan a los tipos agrupados, y las variables ilustrativas, que nos proporciona información sobre la ubicación de los individuos.

11. La probabilidad de que quienes están en este tipo trabajen en empresas pequeñas se multiplica por cinco.

12. Por ejemplo: ecuatorianos (un $85 \%$ de ellos), rumanos (un 75\%) y marroquíes (un 66\%). 
y ubicados en actividades un tanto diferentes a tenor del origen. Los marroquíes tienen un mayor peso en la construcción (un 27\%), en la agricultura (un 23\%) y en la industria (un 20\%). Los rumanos están presentes en la construcción (un 26\%), en la agricultura (un 18\%) y en la industria (un 13\%). La distribución de los ecuatorianos presenta una mayor dispersión: en la construcción (un 22\%), en la agricultura (un 18\%), en la industria y en el comercio (un 13\% en ambos casos). La dispersión de los peruanos es algo mayor y tienen una ubicación diferente: otras actividades (un 20\%), construcción (un 15\%), hostelería (un 14\%), hogar (un 14\%) y comercio (un 13\%). Los ciudadanos de la UE ubicados en el quinto tipo son pocos y tienen su mayor presencia en otras actividades (un 17\%), comercio (un 15\%) y hostelería (un 12\%), entre otros.

Otra característica es la antigüedad, la mayoría de ellos llevan menos de diez años en el mercado de trabajo ${ }^{13}$. Dicho de otro modo, el nivel inferior de peón es un puerto de entrada, de inserción inicial en el mercado de trabajo, a partir del cual se va gestando con el tiempo la movilidad horizontal y vertical de los inmigrantes, lo que parece después depender del capital social, de la edad, de la cualificación profesional, del nivel de estudios y del género, tal como hemos visto en los diversos capítulos de este trabajo. Por último, las mujeres inmigrantes están sobrerrepresentadas en este tipo 5, lo que concuerda con lo que hemos venido argumentando hasta aquí.

En pocas palabras, según el origen, podemos ver cómo hay una mayor concentración en las actividades de construcción y agricultura de rumanos, marroquíes y ecuatorianos, mientras que peruanos y ciudadanos de la UE-15 tienen una mayor dispersión y su presencia es más importante en actividades de cuello blanco. El origen de la oferta de mano de obra y sus características (nivel de educación, lengua, etc.) tiene un papel importante, pero, sin duda, el peso determinante en la estratificación no lo tiene la oferta, sino la demanda. Esto es, las características estructurales de la demanda, como es el sector de actividad y el tamaño de la empresa, influyen más en la clasificación de los cinco tipos examinados.

\section{Algunas conclusiones}

El análisis anterior ha intentado esclarecer qué factores contribuyen en mayor medida a explicar las diferencias en las trayectorias laborales de trabajadores autóctonos e inmigrantes en España. Para hacerlo, hemos usado diferentes instrumentos de análisis cuantitativo. En primer lugar, considerar el salario como indicador de movilidad ascendente. Tal y como se hace desde la perspectiva de la teoría del capital humano, facilita el análisis sobre cuál es el peso relativo de las variables independientes (Sjaastad, 1962). En este estudio y en algunos otros, se ha puesto de relieve el peso que tiene la antigüedad y el hecho

13. El $86 \%$ de los marroquíes ubicados en el quinto tipo están en esa situación. Es más, el $66 \%$ de ellos tiene una antigüedad inferior a los seis años. Los rumanos que están en esta última antigüedad constituyen el $96 \%$ de dicho tipo, y los ecuatorianos, el $79 \%$. 
de que los inmigrantes han tenido una movilidad ascendente «retardada», lo que coincide con el hallazgo de Kogan (2003) y Dickens y McKnight (2008). Sin embargo, también otros estudios han encontrado una movilidad «ascendente y una asimilación ocupacional» más rápida, entre los cinco y los seis años, aunque las diferencias entre nativos e inmigrantes persisten a lo largo del tiempo (Izquierdo et al., 2009). Otra variable explicativa referida a los atributos de los individuos, como el nivel de estudios, tiene una importante capacidad predictiva, mientras las otras, como el género y la edad, tienen un peso menor. Un hecho conclusivo es que la probabilidad de ascenso a los salarios altos disminuye para los inmigrantes en relación con los autóctonos.

En segundo lugar, si consideramos como indicador de movilidad vertical la promoción de categorías profesionales, el análisis de una tipología en la sección III nos permite clasificar la distribución de la población inmigrante en función de tipos de movilidad, lo que, a su vez, nos ayuda a explicar la segmentación del mercado de trabajo (véase Drinkwater et al., 2008). Desde esta perspectiva, la «asimilación ocupacional» resulta distinta: los inmigrantes se concentran fundamentalmente en los tipos 4 y 5 , es decir, en las actividades y en los tipos de empresa que ofrecen menos probabilidades de movilidad ascendente. En otras palabras, la asimilación ocupacional no es general, sino estratificada por origen de la inmigración. La inmigración y determinados grupos de origen se concentran en aquellas actividades que ofrecen más riesgos e incertidumbre, como es el empleo temporal, la baja seguridad en el empleo, los salarios bajos, la ocupación en pequeñas empresas y en sectores más intensivos en mano de obra, como la construcción, la agricultura, la hostelería y el trabajo doméstico. Esto último está relacionado con las propias características de la estructura del mercado laboral español: abundancia de pequeñas empresas y sectores intensivos en mano de obra que no ofrecen muchas oportunidades de promoción profesional, porque sus organigramas jerárquicos son pequeños y no ofrecen oportunidades para las carreras profesionales.

Por último, en tercer lugar, el análisis de regresión logística multinomial nos ha puesto de relieve el peso explicativo que tiene el tamaño de la empresa y el sector de actividad, es decir, variables estructurales habitualmente utilizadas en las teorías de la segmentación, aunque, inmediatamente, hay que señalar que tanto las variables individuales como las estructurales interactúan. Ninguna variable tiene por sí sola suficiente capacidad explicativa. Por consiguiente, el enfoque del capital humano y de la segmentación tienen aspectos importantes de complementariedad entre sí, puesto que son el anverso y el reverso de una misma moneda.

\section{Referencias bibliográficas}

BECKER, G. (1983). «Inversión en capital humano e ingresos». En: TOHARIA, Luis. El mercado de trabajo: teoría y aplicaciones. Madrid: Alianza.

Bloom, D.E.; Grenier, G. y Gunderson, Morley (1995). «The changing labour market position of Canadian Immigrants». The Canadian Journal of Economics, 28 (4), 987-1005. 
BRÜCKER, H. (2009). "Labour mobility in the enlarged EU. Causes, constrints and potencial». En: Nowotny, Ewald; MoOsleChner, Peter y RitZBEerGer-GÜNWALD, Doris. The Integration of European Labour Markets. Edward Elgar Publishing Limited, 67-109.

CACHÓN, L. (2009). La España inmigrante: marco discriminatorio. Mercado de trabajo y politica de integración. Barcelona: Anthropos.

Carrasquer, P.; Martín Artiles, A. y Massó, M. (2007). «La conciliación de la vida laboral y familiar en la negociación colectiva». Papers: Revista de Sociologia, 83.

CASAL, J. (1997). «Modalidades de transición profesional». En: CACHÓN, Lorenzo: Juventudes, mercado de trabajo y política de empleo. Valencia: 7 i Mig.

CEBrián, I. y TOHARIA, L. (2008). "La entrada en el mercado de trabajo: Un análisis basado en la MCVL». Revista de Economía Aplicada, XVI (E-1), 137-172.

CHISWICK, B.C. (2005). "A longitudinal analysis of Immigrant Occupational Mobility: A test of the Immigrant Assimilation Hypothesis». International Migration Review, 39, 332-353.

Coughlan, J.E. (1998). "Occupational mobility of Australia's Vietnamese Community: its directions and Human Capital determinats». International Migration Review, 32 (1), 175-201.

Crouch, C. (2008). The Governance of Labour Market Uncertainty. Towards a New Research Agenda. Berlín: Hugo Sinzheimer Institute.

- (2009). Beyond the flexibility/security trade-off: reconciling confidente consumers with insecure workers. University of Warwick. Seminar Gusto Project.

DÁvila, O. y GHIARdo, F. (2005). "Trayectorias, transiciones y condiciones de empleo en Chile». Revista Nueva Sociedad, 200, 114-126.

DiCKENS, R. y MCKNIGHT, A. (2009). Assimilation of Migrants into the British Labour Market. Londres: CASE. Documento de trabajo.

Doeringer, P. (1985). "Los mercados internos de los empleados». En: Doeringer, P. (comp.). Mercados internos de trabajo. Madrid: MTSS, 187-218.

Domínguez Amorós, M. y LóPEZ-RoldÁn, P. (1996). «La construcció de tipologies: procés i tècniques d'anàlisi de dades». Papers: Revista de Sociologia, 48, 31-39.

Drinkwater, S.; EAde, J. y Garaphic, M. (2008). «Poles Apart?: EU Enlargement and Labour Market Outcomes of Immigrats in the United Kindom». International Migration, 47 (1), 161-190.

ESCRIVÁ, Á. (2000). ¿Empleadas de por vida?: Peruanas en el servicio doméstico de Barcelona. Papers: Revista de Sociologia, 60, 327-342.

European COMmission (2006). Eurobarometer Survey on Geographic and labour mobility. European mobility: first results o fan EU-wide Surrey. Bruselas.

- (2008). "The labour market situation and impact for recent country migrants». En: Employment in Europe. Bruselas: European Commission.

FERrER, A.; GREEN, D.A. y RidDELL, C. (2006). «The effect of literacy on Immigrants Earning». Journal of Human Resources, 41 (2), 380-410.

GaGNON, J. (2009). «Moving out of Bad Jobs: More mobility more opportunity». En: Employment for immigrants. París: OCDE.

GagnON, J. (2009). Job for Immigrants. París: OCDE.

GARrido, L. (2004). Demografía longitudinal de la ocupación. ICE, 815.

Giddens, A. (1991). Sociología. Madrid: Alianza.

Goldmann, G.; Sweetman, A. y Warman, C. (2009). The economic Return Immigrants' Human Capital: The impact of Occupational Matching. Canadian Labour Market and Skills Researchers Network. CLSRN. Working Paper, 21. 
GonZÁleZ, A. (2002). «Efectos macroeconómicos de la inmigración: Impacto sobre el empleo y los salarios de los nativos». Papers: Revista de Sociología, 66, 133-153.

Gordon, I. (1995). "Migration in a segmented labour market». Transactions of the Institute of British Geographers. New Series, 20 (2), 139-155.

GreEN, D.A. (1999). «Immigrant Occupational Attainment: assimilation and mobility over time». Journal of Labor Economics, 17 (1), 49-79.

Henríquez, H. y URibe-Echevarría, V. (2002). «La trayectoria laboral de las personas, un aporte al debate sobre la protección del trabajo». Temas Laborales, 20.

Horan, P.M. (1974). «The structure of occupational mobility. Conceptualisation and Analysis». Social Forces, 53 (1), 33-45.

IZQuierdo, M.; LaCUesta, A. y Vegas, R. (2009). Assimilation of immigrants in Spain: A longitudinal análisis. Documento de trabajo, 4. Banco de España.

Kogan, I. (2003). A Study of Employment Careers of Inmigrants in Germany. University of Mannheim. Documento de trabajo.

LÓPEZ-RoldÁN, P. (1996a). «La construcción de tipologías: Metodología de análisis». Papers: Revista de Sociologia, 48, 9-29.

- (1996b). "La construcción de una tipología de segmentación del mercado de trabajo». Papers: Revista de Sociologia, 48, 41-58.

MCALlister, I. (1995). "Occupational Mobility among Immigrants: The impact of Migration on Economic Success in Australia». International Migration Review, 29 (2), 441-468.

MiguéLEZ, F. y ReCiO, A. (2008). «Spain: large-scale regularisation and its impact on labour market and social policy». Transfer, 14 (4).

Miguélez, F.; Pérez Amorós, F. y ReCiO, A. (2009). Estudi sobre la gestió dels fluxos immigratoris laborals. Centre d'Estudis Quit. Universitat Autónoma de Barcelona.

Ministerio de TRABAJO E INMIGRACIÓN (2009a). La muestra continua de vidas laborales. Descripción general. Disponible en http://www.seg-social.es/prdi00/groups/ public/documents/binario/120735.pdf

- (2009b). La muestra continua de vidas laborales: Cómo se organiza la información. Disponible en http://www.seg-social.es/prdi00/groups/public/documents/binario/120736.pdf

Ministerio de Trabajo y Asuntos Sociales (2006). La muestra continua de vidas laborales. Madrid: Ministerio de Trabajo y Asuntos Sociales. Colección Informes y Estudios, Serie Seguridad Social, 24.

MIPEX (2007). Migrante Integration Policy Index. Londres: British Council.

Miret, P. (2008). Entrar, mantenerse y salir. Biografias laborales en España. Madrid: Ministerio de Trabajo y Seguridad Social (Working Paper)

Miret, P. et al. (2008). Entrar, mantenerse, salir: Biografías laborales en España. Madrid: Ministerio de Trabajo y Asuntos Sociales.

MTIN (2007). "Metodología» En: Muestra continua de vidas laborales. Madrid: Ministerio de Trabajo e Inmigración.

OSTERMAN, P. (1985). Los mercados internos de trabajo. Madrid: MTSS.

Pajares, M. (2008). Inmigración y mercado de trabajo. Informe 2008. Madrid: Observatorio Permanente de la Inmigración. Ministerio de Trabajo e Inmigración.

PARELla, S. (2003). Mujeres, inmigrantes y trabajadoras: La triple discriminación. Barcelona: Anthropos.

Piché, V.; Renaud, J.; Gingras, L. y Shapiro, D. (2002). «Economics Integration of New Immigrants in the Montreal Labour Market: A longitudinal approach». Populations, 57 (1), 57-82. 
Piore, M.J. (1983). «Notas para una teoría de la estratificación del mercado de trabajo». En: TOHARIA, Luis. El mercado de trabajo: teorías y aplicaciones. Madrid: Alianza Editorial.

PIORE, M.J. y SABEL, CH. (1990). La segunda ruptura industrial. Madrid: Alianza.

PolaViejA, J.G. (2003). Estables y precarios. Madrid: CIS.

- (2006). "¿Por qué es tan alta la tasa de empleo temporal?: España en perspectiva comparada». REIS, 11, 77-108.

Pumares, P.; GarcíA, A. y Asensio, A. (2007). La movilidad laboral y geográfica de la población extranjera en España. Madrid: Observatorio Permanente de la Inmigración.

REDSTONE, I. (2006). «Occupational mobility Among Legal Immigrants to the United States». International Migration Review, 40 (4), 854-884.

ReHer, D. y REQUenA, M. (eds.) (2009). Las múltiples caras de la inmigración en España. Madrid: Alianza Editorial.

REHER, D.S. et al. (2007). Informe Encuesta Nacional de Inmigrantes (ENI-2007). Madrid: Instituto Nacional de Estadística.

REYNERI, E. (2006). «De la economía sumergida a la devaluación profesional: nivel educativo e inserción en el mercado de trabajo de los inmigrantes en Italia». REIS, $116,215-235$.

SABEL, CH. (1986). Trabajo y politica. Madrid: MTSS.

SANABRIA, H. (2008). Los inmigrantes colombianos en España: trayectoria y perspectivas. Madrid. Real Instituto Elcano. Working Paper, 3.

SCHAAFSMA, J. y SwEETMAN, A. (2001). "Immigrants Earnings: age at immigration Matters». Canadian Journal of Economics, 34, 1066-99.

SJAASTAD, L. (1962). "The cost and Returns of Human Capital». Journal of Political Economy, 70 (5), 80-93.

SPILlERMAN, S. (1977). "Careers, labor markety structure and socioeconomic achievement». American Journal of Sociology, 83 (3).

TOHARIA, L. y CEBRIÁN, I. (2007). La temporalidad en el empleo: atrapamiento y trayectorias. Madrid: Ministerio de Trabajo y Asuntos Sociales.

TOUSSAINT-COMEAU, M. (2006). «The occupational mobility of Hispanic Immigrants in the US: Evidence from Panel Data». International Migration Review, 40, 508536.

Tubergen, F. (2008). «Occupational status of immigrants in cross-national perspective: A multilevel analyses of seventeen Western societies». En: PARSONS, Craig A. y SMEEDING, Timothy. Immigration and the transformation of Europe. Cambridge: Cambridge University Press.

VILLA, P. (1990). La estructuración de los mercados de trabajo. Madrid: MTSS.

WORLD BANK (2008). Migration and Remittances Factbook. DC. Washington.

ZIMMERMAN, K.F. (2009). «Labour mobility and the integration of European labour markets». En: NOWOTNY, Ewald et al. The integration of European Labour Markets. Cheltenham: Edward Elgar. 


\section{Anexos}

Gráfico 3. Gráfico factorial del análisis de correspondencias con las variables activas y la topología

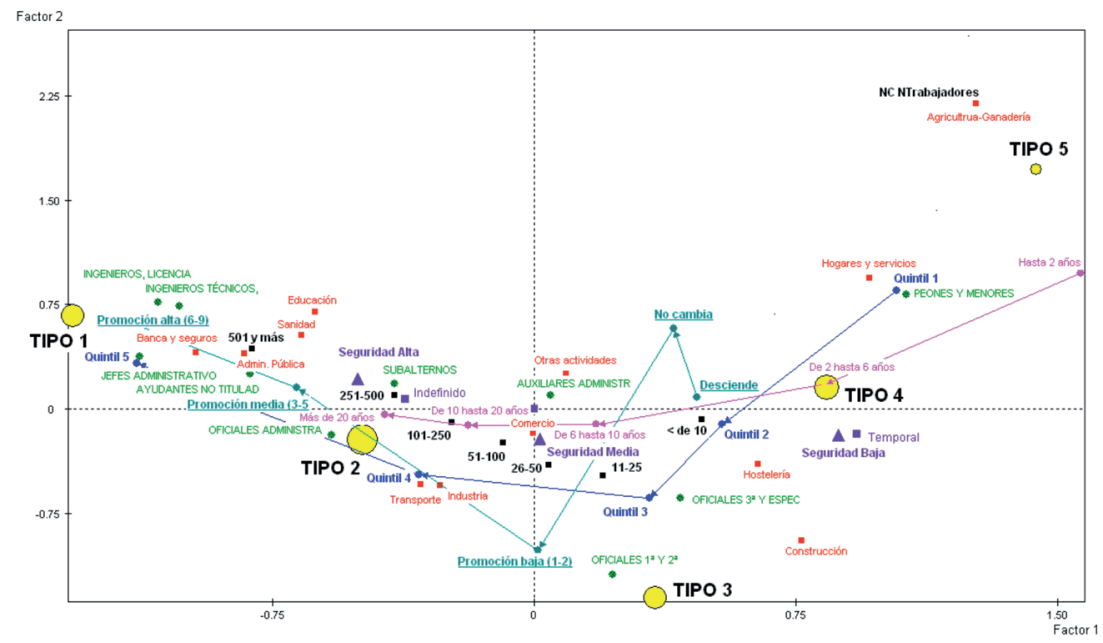

Fuente: Elaboración propia basada en los datos de la MCVL.

Gráfico 4. Gráfico factorial del análisis de correspondencias con las variables ilustrativas y la tipología

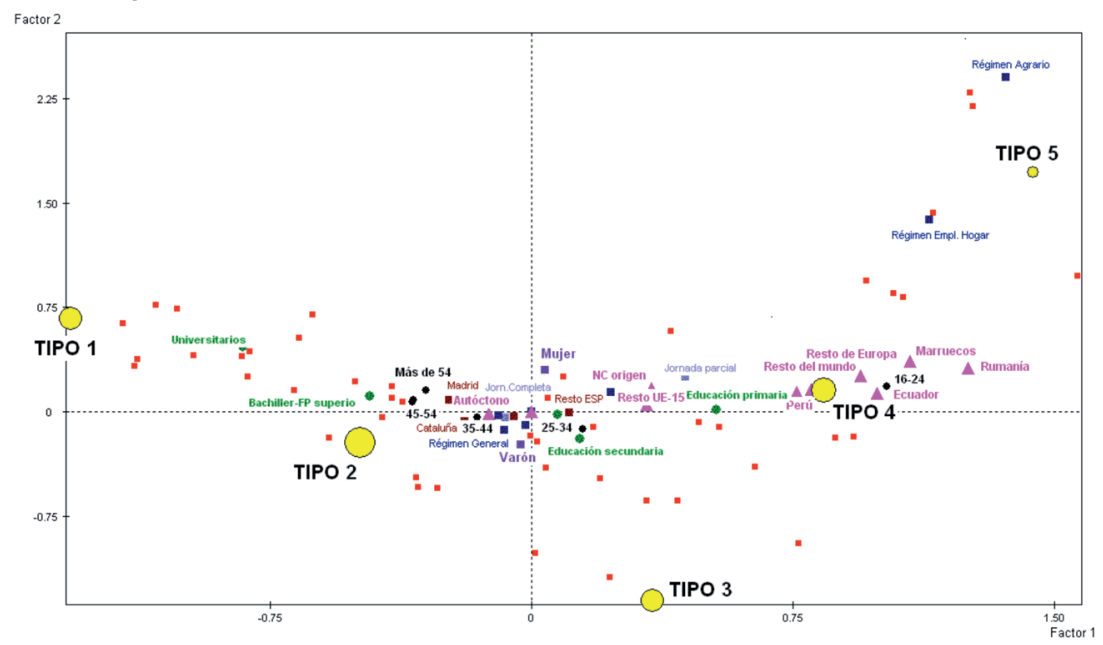

Fuente: Elaboración propia basada en los datos de la MCVL. 